\title{
La fisura regionalista de Graciliano a G. Rosa (la visión hispanoamericana de Emir Rodríguez Monegal y Ángel Rama) \\ Pablo Rocca ${ }^{1}$ | Univesidad de la República - Montevideo, Uruguay
}

Resumo: Este ensaio enfatiza o fato de que nenbum crítico bispanoamericano contemporâneo se ocupou da literatura brasileira, com tanto interesse e persistência, quanto Emir Monegal ou Ángel Rama. Em seus correspondentes mapas e em suas respectivas pesquisas, o regionalismo brasileiro e suas fissuras (nas obras de Graciliano Ramos e de Guimarães Rosa) se nos revelou um relevante ponto de articulação para o confronto de suas produções literárias com outras da literatura hispanoamericana. Palavras-chave: crítica bispano-americana, regionalismo brasileiro, Graciliano Ramos e Guimarães Rosa.

1. Pablo Rocca (Montevideo, 1963). Doutor em Letras pela USP. Pesquisador e professor de Literaturas Uruguaia e Latino-americana da Facultad de Humanidades y Ciencias de la Educación (Universidad de la República, Uruguay), na qual dirige o arquivo literário. Entre seus livros: Historia de la literatura uruguaya contemporánea (1996-1997); El Uruguay de Borges, 2001; Poesía y política en el siglo XIX (Un problema de fronteras), 2003. 


\section{I}

Desde comienzos de los años sesenta hasta principios de la década del ochenta del pasado siglo, Emir Rodríguez Monegal (1921-1985) y Ángel Rama (1926-1983) se ocuparon de modo prioritario y, se diría, totalizador, del discurso literario latinoamericano. En ese común, en general discorde pero en suma complementario plan de trabajo, Brasil conquistó un lugar decisivo. El hecho de que los dos sean uruguayos y, además, rivales, no podría pasar inadvertido, aunque se trata de un problema mucho más complejo que, aquí, no podrá desarrollarse. ${ }^{2}$ Conviene recordar, de cualquier modo, que ningún crítico hispanoamericano coetáneo de la nacionalidad que fuere se encargó, como Monegal o como Rama, con tanto interés y persistencia de la literatura brasileña. En sus correspondientes mapas, en sus respectivas labores críticas, el regionalismo brasileño y sus fisuras (en las obras de Graciliano y de Rosa) fue un punto central de articulación para su lectura confrontada de la literatura hispanoamericana.

\section{II}

Para empezar, ninguna literatura nacional de América Latina interesó a Emir Rodríguez Monegal de modo tan particular como la brasileña, salvo la uruguaya por obvias razones de pertenencia. Ni siquiera la argentina. Es cierto que a pesar de sus reservas crecientes ante el paradigma "literatura nacional", no alcanzó a interponerle objeciones de fondo. Lo mismo ocurrió con Ángel Rama, en cuyo trabajo desde la segunda mitad de la década del sesenta el paradigma de la literatura nacional fue desbordado y de algún modo sustituido por el de literatura latinoamericana. El fuerte proceso homogeneizador del Estado brasileño, así como la unidad y la autonomía del universo de la lengua portuguesa en América, facilitó a los dos críticos un movimiento de cierre sobre el objeto en sí, lo cual habilitaba un grado de coherencia que no podía propiciar el patrimonio común de la lengua española para las fragmentadas repúblicas hispanoamericanas.

2. El problema es tratado en Ángel Rama, Emir Rodríguez Monegal y el Brasil: Dos caras de un proyecto latinoamericano, Pablo Rocca. Montevideo, Ediciones de la Banda Oriental, 2006. Este artículo, en verdad, constituye un pasaje reelaborado del mencionado título que, por lo demás, fue la tesis de doctorado del suscrito defendida en la Universidade de São Paulo. 
Sin embargo, en un estudio sobre "La novela brasileña", que Rodríguez Monegal publicó en 1966, el primer panorama que en lengua castellana se escribió sobre la narrativa brasileña contemporánea, postuló la diversidad geográfica y cultural de Brasil, ${ }^{3}$ concluyendo que "como unidad coherente, no existe, todavía”. Por eso, una perspectiva sincrónica de los escritos e Rodríguez Monegal permite ir más allá de sus numerosas y dispersas intervenciones datadas. Permite visualizar sus obsesiones y modalidades de trabajo, cifrándose en el privilegio de lo propiamente literario antes que en otros discursos con los que considera que los vasos comunicantes son débiles o sospechosos de desvío de la norma literaria. En esa operación, Monegal prefiere el autor notable o, mejor, uno o más textos que preservando la marca de autoría desautomatizan las formas consagradas (llamémosle la antología). Luego, haciéndolo depender de la antología, estudia la corriente, la escuela o el movimiento literarios, ambiguamente sostenidos por el arco temporal y - a menudo - en relación de contigüidad con experiencias similares en otras latitudes, en otras lenguas y literaturas (llamémosle las series).

En la antología de Monegal tanto la obra de Graciliano Ramos como la de Guimarães Rosa ocuparon un sitio decisivo. Del mismo modo que, en sus recortes de series, la cuestión del regionalismo lo preocupó a lo largo de toda su carrera. En su estudio practicó el ensamblaje comparatista de la antología brasileña con la antología hispanoamericana, en base a las propiedades intrínsecas de una obra o como manifestaciones de una poética. Para montar este dispositivo dialogó con la crítica brasileña, sobre todo la de su tiempo.

Pero hubo un tiempo lejano en que el aprendiz de crítico, de apenas 23 años de edad, se enfrentó a una traducción uruguaya de Angústia. Y en su reseña, por lo demás una de las primeras que escribió en su vida, no se dejó convencer por la novela ni por la traducción:

3. "Debido a las vastas diferencias naturales entre la selva amazónica y el desierto del Nordeste, las áridas mesetas de Minas Gerais y la blanda, sensual, costa de Rio de Janeiro, los húmedos bosques de Santa Catarina y los templados espacios abiertos de Rio Grande do Sul, el Brasil abarca una enorme variedad de culturas" (Rodríguez Monegal, "La novela brasileña”, 1977: 291).

4. Sin haber leído el original, Monegal dice de la traducción de Serafín J. García a la edición uruguaya de Angústia (Montevideo, Ed. Independencia, 1994): "Aunque no he podido consultar el texto original, estoy seguro que en muchas oportunidades donde García traduce usted, Ramos usó el familiar y más confianzudo você. Estos pequeños detalles empañan algo la traducción". 
La ejecución del tema transparenta su pobreza creadora, su limitación imaginativa. Un examen rápido lo mostrará. La novela está escrita en primera persona (recurso de principiante). [... Es claro que Ramos sabía lo que arriesgaba y prefirió, pese a todo, el enfoque centrado y unilateral, que unifica pero hace monótona la obra. [...] Donde se evidencia mejor la relativa incapacidad creadora de Ramos es en el desarrollo de la trama. No me refiero a la vulgaridad de ciertas escenas (vulgaridad inherente al personaje). Me refiero al tejido de causalidades y de azares que afligen las páginas de este libro.

Todo esto, concluye el joven crítico, muestra "muy claramente que Ramos no es un auténtico novelista, aunque sea un escritor estimable" (Rodríguez Monegal, 5/X/1945). En rigor, nada podía decirle una novela que no encajaba en la narrativa de vanguardia metropolitana, a la que en aquellos tiempos de intervención tajante en el campo literario Monegal tomaba como modelo sumo para la edificación de la nueva literatura americana. Muy poco significaba, además, si esa novela venía en traducción de Serafín J. García, un escritor realista criollo a quien el joven agresivo había desplazado de esas páginas literarias del semanario Marcha; menos podía importarle aun si los tormentos interiores de Luís da Silva le parecían insuficientemente elaborados desde el psicoanálisis, que entonces descubría y aplicaba con devoción. ${ }^{5}$ A contrapelo de la práctica habitual en sus reseñas, Monegal no alude en este comentario a ninguna novela anterior ni posterior de Graciliano. Esto le impide situar su narrativa en el arco regionalista, un poco porque Angústia es la menos situada en este registro. Y más aun porque es muy probable que entonces no las conociera.

Dos décadas le llevaría superar esta carencia del artículo juvenil y prepotente. Primero ubicaría a Graciliano entre los regionalistas nordestinos. Pero en una situación incómoda, en un lugar que ya no dependía de las variables con las que ordenó la narrativa latinoamericana en su primer trabajo sinóptico, cuando pensó ese conjunto desde la disyuntiva entre realismo y literatura fantástica y subordinó, a regañadientes, la producción de la primera columna a la fuerza de la geografía, el hombre y el medio, según era usual en la crítica positivista de entonces (Rodríguez Monegal. La narrativa hispanoamericana...,

5. En 1966 seguirá despreciando este aspecto de la novela: en Vidas secas, apunta que Graciliano "evita todo análisis psicológico (había abusado del género en una novela anterior, Angústia, 1936) [...]" (Rodríguez Monegal, "La novela brasileña", 1977: 299). La misma opinión se repite, literalmente, en el artículo sobre Graciliano y el regionalismo nordestino, en 1983. 
27/VI/1952). No colocó a Graciliano dentro de este grupo ni en tal estudio precursor ni en el ensayo que hizo sobre Lins do Rego en 1953. Con todas las cartas a la vista, está claro que Monegal comenzó a interesarse por esta obra en el panorama "La novela brasileña", cuando integró a Graciliano Ramos en el conjunto de los regionalistas nordestinos, al tiempo que lo desmarcó de este grupo presentándolo como antecedente de Guimarães Rosa. Le pareció, entonces, que era un autor preocupado "por escribir bien" a diferencia de quienes llamó "cuentistas natos": Lins do Rego y Jorge Amado (Rodríguez Monegal, "La novela brasileña”, 1977: 298).

Evidentemente, ese redescubrimiento se abastece de un prestigio ganado por la obra de Graciliano entre la crítica literaria brasileña, a la que en su artículo de 1966 invoca con vaguedad: "Algunos críticos han proclamado a Vidas secas (1938) su obra maestra y una obra maestra de la novela regional. El juicio es discutible pero, aun si no la considera como tal, es un libro importante y tal vez el mejor de los suyos" (Destacados nuestros, 299). Si en 1952 veía una falsa oposición entre universalismo y regionalismo y centraba "el verdadero problema" entre lo realista y lo fantástico, Monegal no lograba sacudirse las categorías de tiempo, paisaje y sociedad para entender la corriente regional americana, aunque esta tríada se le aparecía como exógena o "extraliteraria", como acostumbraba decir. En cambio, en 1966 opuso el "problema geográfico" al "literario": "importa poco cuál es la situación geográfica de un escritor. Lo que realmente importa es la naturaleza de su enfoque de la realidad. [...] Es esta diferencia de profundidad, y no la diferencia en el tema, lo que hace a Amado más regional que Ramos" (300-301). En uno de los últimos trabajos de su vida, titulado "Graciliano Ramos y el regionalismo nordestino" (1983), quiso cerrar el balance de todo lo actuado. Como si fuera un palimpsesto, escribió sobre el artículo anterior, retocando algunas observaciones, adicionando un código actualizado por lecturas de la "nouvelle critique" que no podía tener en 1966 y se mostró discorde, por primera vez, con algunas opiniones que antes sólo había invocado parcial o genéricamente:

El problema del regionalismo, tal como fue discutido en los años veinte y treinta en América Latina, es un problema falso. Entonces fue presentado más como problema geográfico que literario. [...] Una diferencia estructural, a pesar de la semejanza temática, separa la obra de sus más notorios practicantes. En tanto que José Lins do Rego y Jorge Amado se sitúan del lado del 
regionalismo pintoresco, Graciliano Ramos se instala, hondamente, en el regionalismo esencial (Rodríguez Monegal, octubre de 1983: 34).

La estrategia narrativa del regionalismo nordestino, encastrado en el hispanoamericano (el de Rivera y Gallegos, el de Güiraldes y Martín Luis Guzmán, entre otros), fue visto por Monegal, por primera vez, creando "descripciones minuciosas de una realidad ajena que el autor componía para lectores también ajenos a ella. El agudo análisis de William Empson (Some Versions of Pastoral) fue totalmente desoído por críticos que habían leído a Lukacs y a Goldmann, que siempre citaban al peor Sartre, pero eran analfabetos en formalismo. New Criticism o el estructuralismo germánico" (35). Este comentario va al choque contra la interpretación de Carlos Nelson Coutinho y Leonidas Cámara, que lee en el colectivo coordinado por Sonia Brayner (Graciliano Ramos, Rio de Janeiro, 1977). Pero otra vez, tras esa condena, se asoma la silueta del otro, connotado por una dialéctica que hace presente al ausente.

En efecto, un año atrás, en la introducción a Transculturación narrativa en América Latina, el otro, Ángel Rama, había propuesto que el "discurso literario de la novela regionalista respondía básicamente a las estructuras cognoscitivas de la burguesía europea", prefiriendo trabajar sobre las contradicciones o las vecindades entre la narrativa vanguardista y una triple frontera oscilante entre la novela regional, la novela social y la realista crítica. En esta última menciona a Graciliano Ramos (Rama, Transculturación..., 1982: 48-49 y 52). A contrapelo de esta lectura, para Monegal, Graciliano importa como el mejor de su serie y, en ella, Vidas secas se destaca porque trasciende lo social gracias a una condensación lingüística entre la expresión más austera y el silencio que lo hace escapar del realismo fotográfico y de la llana denotación del mensaje político:

Con la perspectiva actual es fácil comprender por qué un libro tan fatalista fue celebrado hasta por la izquierda más militante. A riesgo de mal interpretar el libro, la crítica prefirió verlo como un documento sobre la injusticia de un sistema paternalista y casi feudal. Subrayaron lo que Vidas secas tenía de escueta denuncia; se saltaron lo que era, en definitiva, una visión pesimista del hombre y la sociedad del Nordeste (38).

Por las referencias acusadas en su artículo, esa crítica militante de izquierda parece más una deducción que una línea continua y vigorosa, 
ya que si Monegal toma contacto con el corpus básico de la recepción crítica sobre Graciliano a partir del volumen colectivo antes mencionado, en cambio no da muestras de haber leído los primeros estudios sobre el narrador alagoano, el de Lúcia Miguel-Pereira (en Boletim Ariel, 1938) ni las notas de Antonio Candido (Ficção e confissão, 1956) ni el libro de Rolando Morel Pinto (Graciliano Ramos, autor e ator, 1962). Como sabemos, estos estudios lejos están de situar a Vidas secas en el ángulo de la pura denuncia militante. Tratando de rebatir una vertiente que sospecha hegemónica, Monegal aporta en 1983 dos hipótesis. La primera, que Caetés vendría a ser una polémica secreta con el "Manifesto Antropófago"; la segunda, que la obra entera de Graciliano Ramos representa una solitaria variación del regionalismo, que ahora llamará "esencial" y "psicológico". Esta última, como vimos, está insinuada en su juvenil reseña de 1945. Pero ahora, en lugar de restarle jerarquía a la exploración de los infiernos interiores del protagonista de una novela, ve el conjunto de una obra en cotejo con la vida del escritor - como lo había hecho con Neruda, Quiroga y Borges -, y Ramos se levanta ante sus ojos como un Dostoiewski y un Flaubert americano. Sin el fragor psicoanalítico de Monegal, quien encuentra huellas autobiográficas en la cruda infancia del protagonista de la novela homónima o en la humillación de Fabiano en Vidas secas o en los tormentos interiores de Luís da Silva, en un ensayo clásico que el crítico uruguayo no cita, Antonio Candido había postulado que en esta última novela "contém muito de Graciliano Ramos, tanto no plano consciente (pormenores biográficos) quanto no inconsciente (tendências profundas, frustrações), representando a sua projeção pessoal até aí mais completa no plano da arte" (Candido, Ficção e confissão..., 1992: 43).

Rodríguez Monegal combina dos soluciones, la secreta polémica por la relectura del arte nacional y la luminosa oscuridad del yo en la ficción,

\footnotetext{
6. La nota 6 a su artículo dice: "El pesimismo de Graciliano Ramos ha sido señalado, entre otros, por Otto Maria Carpeaux, Antonio Candido, Alvaro Lins, Olívio Montenegro y Rolando Morel Pinto. Para una discusión, véase el artículo de Franklin de Oliveira en la recopilación citada de Sonia Brayner". En una nota posterior remite a un estudio de Otávio de Faria. En su ensayo sobre Lins do Rego, de 1953, se había apoyado en opiniones, que a veces discute, de Gilberto Freyre, Mário de Andrade, Otto Maria Carpeaux y Lia Correa Dutra. Mientras que en sus artículos sinópticos, salvo en los que reúne en el libro El boom de la novela latinoamericana, no hace referencia a crítico alguno.
} 
con su vieja convicción de que el arte literario sólo se vincula con el referente en un sentido débil y que se torna arte cuando lo supera y multiplica. Así relee la obra de Graciliano y, por su intermedio, redefine el regionalismo buscando obturar las viejas interpretaciones positivistas, la lectura política de la literatura y, sobre todo, la nueva vía transculturadora de su siempre rival Ángel Rama. De nuevo, como en 1952, disuelve la polémica entre universalismo y regionalismo, ahora con más precisiones, postulando que la literatura se hace desde lo interior, que es una máscara de la identidad; se hace de literatura proveniente de cualquier latitud antes que de ser una manifestación refleja del medio en que se teje la narración.

En 1953 la mejor alternativa para la narrativa brasileña le parecía que estaba en la "objetividad" de los relatos de Lins do Rego, es decir el trasvasamiento de lo exterior a lo interior y, por la suma armoniosa de los dos factores, la producción de un hecho estético cabal, libre de denuncias políticas de facción y de pintoresquismos. Esa era, en otro términos, su definición de entonces del regionalismo "esencial", que también veía en la narrativa misionera de Horacio Quiroga. Por aquella fecha, ignorando la contribución de la vanguardia -y, en especial, de su luego tan admirado Oswald de Andrade-, pensaba que la literatura de Brasil era la expresión magnificente de la varia naturaleza (incluida su multiforme urbanización), y como tal debía tomar la ruta del regionalismo "para alcanzar ese universalismo brasileño que, al fin y al cabo, es el de todos, en América" (Rodríguez Monegal, "José Lins do Rego...", 1977: 333). La senda de la tradición era, en una hipótesis que no dejaba a un lado la inmadurez de América para el arte, más apropiada que la de la renovación, dicotomía que volverá a manejar en otro artículo de 1972 (Rodríguez Monegal, "Tradición y renovación...", 1972). Dicho en otros términos, Monegal creía que era necesario pagar este impuesto para superar la mimesis de lo metropolitano, rebasarla por medio de la absorción sintética de todas los cauces que provenían de ella. Treinta años después, el crítico descubre que es más productiva la "subjetividad" de Graciliano que la "objetividad" del realista coetáneo. De ahí que lo vea como un escritor-bisagra, que se reengancha con una obra que ya había superado estas tensiones en Machado de Assis y que prepara el terreno para que la tradición se refine y se cruce con la renovación en el "mestre Guimarães". Más que regionalista, es decir, más que el miembro de un grupo fácilmente dibujado en el contorno, le importa la vindicación del solitario, del creador, de la obra misma antes que la historia: 
Con la perspectiva de casi treinta años de su muerte, ya parece posible leer a Graciliano Ramos como lo que es: el mayor novelista brasileño de la primera mitad del siglo XX, el único que puede situarse (sin concesiones) entre Machado de Assis y Guimarães Rosa, y no apenas como el mejor de los regionalistas (41).

\section{III}

Sólo después del llamado de atención que su amigo Walter Wey le hizo en Montevideo "a comienzos de los años sesenta", conocería, deslumbrado, la obra de Guimarães Rosa. Aunque escribió sobre la novela en 1966, según él mismo lo confiesa, sólo podrá leerla gracias a la traducción española de Ángel Crespo. Es una historia casi paralela a la de Rama, por más este se entera con más detalles de la obra cercana y transformadora del escritor mineiro como escucha de la disertación que Candido hace en 1960 en la Universidad de la República. Candido, Rama, Monegal y Guimarães Rosa coinciden en un Congreso celebrado en Génova, en 1965 (Rama, "Coloquio de Génova..., 1965).

En el correr de los años sesenta, Monegal va tramando relaciones en Brasil que lo familiarizan con su cultura y, también, con la crítica literaria. Eso explicaría por qué va cambiando el lugar del objeto Grande sertão: veredas en el cuadro de relaciones literarias latinoamericanas. Para empezar, en el artículo panorámico de 1966, postula que la novela desbloquea el "callejón sin salida" del regionalismo de los años treinta. Lo hace porque aun expresando un mundo violento, no se queda en el plano sociológico - como Euclides da Cunha en Os sertões, dice - sino que se instala en un territorio mitopoético, donde por la fuerza "de la poesía concreta de su dicción y de los personajes" crea un lenguaje nuevo, hecho de "relatos vueltos a contar y reescritos por la imaginación de Guimarães Rosa" (305). El suyo es, entonces, "un mundo esencialmente verbal", aprendido en la técnica más alambicada de Joyce, Faulkner, Proust, Mann y Sartre (sobre todo en los dos primeros) y en la corriente del relato tradicional, si bien este último motivo no lo desarrolla. En El boom de la novela latinoamericana, de 1972, Monegal propone que Guimarães ocupa una posición de jerarquía similar a la de Borges, y que su ejemplo para quienes irrumpen hacia mediados de los sesentas se puede bifurcar como antecedente por la sabia dosificación de lo tradicional con la novedad técnica de la narrativa del siglo XX (la llave para entrar en la edad 
adulta de una literatura) y, además, como inventor de un universo mítico aun más complejo que el de Pedro Páramo (la inmersión en los relatos universales desde las fuentes americanas). También en 1972, y sin conocer este libro de Monegal, Candido veía a Guimarães y a Rulfo - junto a otros narradores hispanoamericanos - como importadores de las técnicas que desentumecen el realismo decimonónico al cruzar vanguardia con raíces populares, pero se levantaba sobre la exclusiva valoración de las formas entendiendo que su literatura significaba un acto de compleja interpretación de la "conciencia dilacerada del subdesarrollo" (Candido, "Literatura y subdesarrollo", 1972). Como se dijo, en 1982 Rama pensará que la literatura sale de su propia esfera para volverse un discurso conexo a otras disciplinas, que le permiten rehacerse y conocer los sujetos populares y la vida cultural latinoamericana en sus diferentes capas, a veces superpuestas.

En rigor, Ángel Rama verá en la obra de Guimarães Rosa el cumplimiento de la madurez de la literatura latinoamericana, por medio de una prodigiosa invención lingüística "que implica forzosamente la previa determinación de las leyes de su funcionamiento", pero prevé un despegue argumental que su compatriota omite. Para Rama todo ese aparato estético se funda en algo más que un conocimiento de la región a la que pertenecía el autor y pertenecen sus criaturas de ficción, ya que Guimarães Rosa "se formó, desde la infancia, en el río de una cultura. Una cultura creada por un pueblo a lo largo de siglos dentro de un original crisol de tendencias y valores" ("João Guimarães Rosa", 1975: 80). Así puede invertir el razonamiento de Monegal que propone ver en Rosa una doble operación constructiva realizada al mismo nivel y al mismo tiempo: escribir como Joyce o Faulkner y reconstruir la oralidad desde el artificio vanguardista. Para Rama la actualidad de Guimarães defendida por Haroldo de Campos, quien lo sitúa más cerca del nouveau roman que de la novela burguesa del XIX, ${ }^{7}$ se debe a que el escritor mineiro fractura la serie realista de la que se sirve el regionalismo, recusando "centralmente la escritura literaria preexistente", así como rechaza la "convención hablada vigente". Es el habla popular la que se jerarquiza por cuenta de una investigación y un enriquecimiento que proveen otras nutrientes, mucho más allá del mero artificio técnico, "con lo cual presenciaríamos la

7. Cita de de Campos, Metalinguagem, 1970, en Rama ("João Guimarães Rosa", 1975: 85). 
paradojal situación de que un escritor del regionalismo, profundamente inmerso en su medo cultural, [...] consigue romper las convenciones fijadas por la literatura culta urbana" (85). A esa nostalgia por una autoctonía cultural americana que sabe explotar con inteligencia sus estructuras populares, que contienen -O aun prefiguran- las operaciones efectuadas por la metrópoli, Rama la llamará narrativa "transculturada".

En suma, donde Rama encuentra el hilo de oro de la literatura latinoamericana por el peso del tiempo, la tradición, la lengua y la cultura, Monegal niega el rigor de la concatenación causal y prefiere la estrategia del anacronismo y la paradoja. Monegal no puede salir de una lectura esteticista con débiles marcas - cada vez más borrosas - del contexto, mientras que Rama se recostará a una lectura culturalista, por la cual ningún hecho estético que vinculara lo culto con lo popular, y menos Grande sertão: veredas, podía escapar a una apertura de discursos, si no quería caer en anacronismos o simplificaciones.

Resumen: Conviene recordar que ningún crítico bispanoamericano coetáneo de la nacionalidad que fuere se encargó, como Monegal o como Rama, con tanto interés y persistencia de la literatura brasileña. En sus correspondientes mapas, en sus respectivas labores críticas, el regionalismo brasileño y sus fisuras (en las obras de Graciliano y de Rosa) fue un punto central de articulación para su lectura confrontada de la literatura bispanoamericana.

Palabras Claves: crítica hispano-americana, regionalismo brasileño, Graciliano Ramos y Guimarães Rosa.

\section{Referências Bibliográficas}

CANDIDO, Antonio. Ficção e confissão. Ensaios sobre Graciliano Ramos. Rio de Janeiro: Editora 34, 1992. [Originalmente notas aparecidas en Diário de São Paulo em 1945, salvo el último texto "A cinqüenta anos de Vidas secas"]

Literatura y subdesarrollo. In: FERNÁNDEZ MORENO, César (Coord. e introducción). América Latina en su literatura. México: Siglo XXI/UNESCO, 1972. p. 335-353.

RAMA, Ángel. Coloquio de Génova: Dos tareas que valen un viaje. Marcha, Montevideo, n. $1.245,28-29,26$ fev. 1965. 
Disponivel em: http://www.letras.ufmg.br/poslit

RAMA, Ángel. João Guimarães Rosa. In: RAMA, Ángel (Selección, prólogo y notas). Primeros cuentos de diez maestros de la narrativa latinoamericana. Barcelona: Planeta, 1975. p. 7389.

. Transculturación narrativa en América Latina. México: Siglo XXI, 1982.

RODRÍGUEZ MONEGAL, Emir. Una novela brasileña. Angustia de Graciliano Ramos. Marcha, Montevideo, n. 302, p. 14, 5 out. 1945. [Reseña de una edición uruguaya de Angustia. Montevideo: Editorial Independencia, 1944, traducida y prologada por Serafín J. García]

. La narrativa hispanoamericana. Tendencias actuales. Marcha ( $2^{\circ}$ sección), Montevideo, n. 628, p. 25-26, 27/VI/1952. [Reproducido, con mínimas variantes, con el título "Un panorama", en Narradores de esta América. Montevideo: Alfa, 1961: 11-20. Con el título "La crisis del realismo", en Narradores de esta América, $2^{\underline{a}}$ ed. ampliada. Buenos Aires: Alfa Argentina, 1974, tomo I: 316-334. Edición definitiva: 1977. Incluye referencias a Mário de Andrade, José Lins do Rego y Jorge Amado]

José Lins do Rego y algunos problemas de la novela brasileña. Montevideo: Instituto de Cultura Uruguayo-Brasileño (Serie "Conferencias"), 1953. [Republicado con modificaciones con el título "En la muerte de un creador: Mundo novelesco de Lins do Rego”, en Marcha, Montevideo, n. 880, p. 22-23, 20 set. 1957. Integrado a Narradores de esta América. Montevideo: Alfa, 1961: 121-138. $2^{\underline{a}}$ ed. ampliada: Buenos Aires: Alfa Argentina, 1974, tomo I: 316-334. Edición definitiva: 1977]

. La novela brasileña. In: Narradores de esta América, tomo I. Buenos Aires: Alfa Argentina, 1974. p. 291-315. Edición definitiva: 1977. [Versión original, a la que se agrega una coda algo rectificatoria, salió en Mundo Nuevo, París, n. 5, diciembre 1966: 5-14. Versión en inglés del mismo trabajo en Daedalus, Boston, setiembre 1966]

. En busca de Guimarães Rosa. In: Narradores de esta América, tomo I. Buenos Aires: Alfa Argentina, 1974: 335-354. Edición definitiva: 1977. [Originalmente en Mundo Nuevo, París, n. 5, febrero 1968: 4-16. Refundido como prólogo a Primeras Historias, de J. Guimarães Rosa. Barcelona, Seix Barral, 1969]

La nueva novela latinoamericana. In: Narradores de esta América, tomo I. Buenos Aires: Alfa Argentina, 1974: 11-36. Edición definitiva: 1977. [Datado en 1969]

. El boom de la novela hispanoamericana. Caracas: Tiempo Nuevo, 1972. [Pese al título, incluye referencias a numerosos autores y críticos brasileños, leídos en paralelo con la producción hispanoamericana. Con el título "Notas sobre (hacia) el boom", originalmente como una serie de cuatro artículos, apareció en Plural, México, n.. 4-6-7-8, enero a mayo de 1972]

. Tradición y renovación. In: FERNÁNDEZ MORENO, César (Coord. e introducción). América Latina en su literatura. México: Siglo XXI/UNESCO, 1972. p. 139-166.

. Anacronismos: Mário de Andrade y Guimarães Rosa en el contexto de la novela hispanoamericana. Revista Iberoamericana, Pittsburgh, n. 98-99, p. 109-115, jan.-jun. 1977.

Graciliano Ramos y el regionalismo nordestino. Revista de la UNAM, Nueva época, v. XXXIX, n. 30, p. 34-41, out. 1983. 